Journal of Crystal Growth 339 (2012) 13-21

\title{
Growth of AIN bulk crystals on SiC seeds: Chemical analysis and crystal properties
}

Matthias Bickermann ${ }^{*, 1}$, Octavian Filip ${ }^{2}$, Boris M. Epelbaum², Paul Heimann², Martin Feneberg ${ }^{3}$, Benjamin Neuschl ${ }^{4}$, Klaus Thonke ${ }^{4}$, Elke Wedler ${ }^{5}$, and Albrecht Winnacker ${ }^{1}$

${ }^{1}$ Department of Materials Science 6 (I-MEET), University of Erlangen, Martensstr. 7, 91058 Erlangen, Germany

${ }^{2}$ CrystAl-N GmbH, Am Weichselgarten 7, 91058 Erlangen, Germany

${ }^{3}$ Institut für Experimentelle Physik, Abt. Experimental-/Materialphysik, Otto-von-Guericke-Universität Magdeburg, Universitätsplatz 2, 39106 Magdeburg, Germany

${ }^{4}$ Institut für Quantenmaterie/Gruppe Halbleiterphysik, Universität Ulm, Albert-Einstein-Allee 45, 89081

Ulm, Germany

${ }^{5}$ Institut für Festkörperphysik, Friedrich-Schiller-Universität Jena, Max-Wien-Platz 1, 07743 Jena, Germany

* Corresponding author: Tel.: +49-9131-8527730, Fax: +49-9131-8528495,

Email: matthias.bickermann@ww.uni-erlangen.de

Keywords: A1. Impurities; A1. Optical properties; A2. Growth from vapor; B1. Aluminum nitride

Highlights:

- Different growth conditions used to control SiC incorporation in AIN bulk growth

- Phonon energies and band-gap of the crystals close to 'pure AIN'

- Deep-UV opacity regardless of silicon and carbon content

- Two types of samples with very different absorption and luminescence

- No pseudo-binary alloy, but highly compensated, Si/C co-doped AIN

\section{Abstract}

AIN single crystals are grown by physical vapor transport (PVT) in sintered TaC crucibles in the presence of $\mathrm{SiC}$, i.e. by seeding on $6 \mathrm{H}-\mathrm{SiC}$ or by adding $\mathrm{SiC}$ to the AIN source material. Different growth conditions, i.e. growth temperatures $T=1900-2050^{\circ} \mathrm{C}$ and off-orientation angles in respect to [0001] $\varphi$ $=0-42^{\circ}$, are applied in order to investigate to which extent the incorporation of $\mathrm{Si}$ and/or $\mathrm{C}$ can be controlled during PVT growth. Chemical analysis is performed by energy-dispersive X-ray analysis (EDX), secondary ion mass spectrometry (SIMS), and Rutherford backscattering spectroscopy (RBS). The grown crystals are significantly contaminated with $\mathrm{Si}$ and $\mathrm{C}$ in the range of several atomic percents, but they do not represent pseudo-binary AIN-SiC solid solutions. Samples cut from these crystals are probed by Raman micro-spectroscopy, optical absorption, cathodoluminescence (CL), and near band-gap photoluminescence $(P L)$ in order to evaluate the crystal properties. All crystals exhibit phonon bands at the positions of AIN phonon energies, and a low-temperature band-gap exceeding $5.8 \mathrm{eV}$, which is only slightly lower than the band-gap of pure AIN. On the other hand, the samples show very different optical properties below the band-gap, including coloration. As the changes in optical properties do not correlate to chemical analysis, we suggest that self-compensation of silicon 
and carbon as well as formation of intrinsic defects lead to a complex compensation scenario in the samples. The grown crystals are thus to be considered as highly compensated, Si/C co-doped AIN.

\section{Introduction}

Single-crystalline aluminum nitride (AIN) is a very promising substrate material, e.g. for nitride based optoelectronic devices performing in the deep ultraviolet (UV) spectral range. The feasibility of bulk AIN growth using a physical vapor transport (PVT, also known as sublimation-recondensation) technique has been demonstrated in detail [1]. However, large AIN substrates of high crystalline quality are in fact not made available until now.

One method to quickly reach industrial relevant wafer sizes, preferably two inch or larger in diameter, is to employ silicon carbide ( $\mathrm{SiC}$ ) seeds. SiC bulk crystal growth is more mature and large area substrates are commercially available. Several research groups have thus investigated bulk AIN growth on $\mathrm{SiC}$ seeds. However, as $\mathrm{SiC}$ is chemically attacked under AIN growth conditions, the resulting bulk crystals are significantly contaminated with $\mathrm{Si}$ and $\mathrm{C}$ up to the range of several atomic percents. In the current study we want to discuss the nature of such 'contaminated AIN crystals' investigating the impact of growth parameters on chemical composition and crystal properties.

Several research groups including our group have investigated initial stages of AIN growth on SiC in order to understand growth start, coalescence, and reduction of dislocation density, see e.g. [2-14]. On the other hand, only a few studies report on chemical composition or optical properties of bulk AIN single crystals grown on $\mathrm{SiC}$ seeds or with $\mathrm{SiC}$ added to the source material. The main results are summarized below:

Balkaş et al. [15] were the first to report on PVT growth of AIN on (0001)-oriented 6H-SiC seeds. They used graphite crucibles and insulation, and growth temperatures in the range of $1950^{\circ} \mathrm{C}$ to $2250^{\circ} \mathrm{C}$. The crystals obtained at growth temperatures above $2050^{\circ} \mathrm{C}$ had bluish to greenish coloration; in respect to colorless crystals grown at lower temperatures, the $\mathrm{Si}$ and $\mathrm{C}$ concentrations were enhanced by about two orders of magnitude. Later, Wang et al. [16] grew AIN on C-face (000-1) 6H-SiC seeds in a similar graphite based set-up, yielding bluish crystals independent on growth temperatures up to $2100^{\circ} \mathrm{C}$.

Shi et al. [17] used a sintered AIN-SiC compound source and Si-face $6 \mathrm{H}-\mathrm{SiC}$ seeds with AIN epitaxial layers on top to grow AIN-SiC films in tungsten crucibles at $1800^{\circ} \mathrm{C}$. They found an Al:Si ratio of $4: 1$ in the crystals independent of the source composition. Gu et al. [18,19] mixed AIN and SiC powders to obtain AIN-SiC bulk crystals. PVT growth was performed in graphite or graphite/TaC based set-ups at temperatures in the range of $1800-2000^{\circ} \mathrm{C}$. Si-face (0001) SiC seeds with off-orientations up to $8^{\circ}$ were used to improve surface morphology. Colorless to dark green crystals were produced, depending on growth temperature. Chemical analysis of the crystals showed Al:Si ratios of roughly 3:1 independent of the ratio of AIN and $\mathrm{SiC}$ in the source material. A dependence on growth temperature indicated that the Al:Si ratio in the crystals was governed by the partial pressure of the species. Conflicting statements are given on whether the $\mathrm{Si} \mathrm{C}$ ratio in the crystals was stoichiometric or not.

Dalmau et al. $[20,21]$ investigated AIN growth on Si-face (0001)-oriented $6 \mathrm{H}$-SiC seeds with an AIN epitaxial layer on top. Growth was performed in sintered TaN crucibles at temperatures of 1850 $2000^{\circ} \mathrm{C}$. The contamination with silicon and carbon in the crystals was found to be only $160-300 \mathrm{ppm}$ wt, while oxygen remained the dominant impurity with up to $1.200 \mathrm{ppm}$ wt. The crystals were essentially colorless. While the main area was Al-polar AIN, formation of inversion domains (i.e., N-polar AIN) was regularly observed.

Mokhov et al. [22-24] used in-situ carbonized tantalum crucibles to grow AIN on $6 \mathrm{H}-$ and $4 \mathrm{H}-\mathrm{SiC}$ seeds of either polarity at temperatures ranging from $1900^{\circ} \mathrm{C}$ up to $2300^{\circ} \mathrm{C}$, although the lower temperature is preferred. Regardless of seed polarity, the grown layer was always Al-polar. The resulting 
crystals had a yellowish, sometimes brownish coloration; they were contaminated with silicon (3-6\% at) and to a lower extent with carbon $(0.04-0.14 \%$ at) [25]. A linear variation of the lattice constant with Si contents up to $8 \%$ at was observed. Sumathi et al. [26] produced AIN single crystals on Sipolar $(0001) 6 \mathrm{H}-\mathrm{SiC}$ in carbonized tantalum crucibles at temperatures in the range of $1800-1900^{\circ} \mathrm{C}$; their yellowish crystals also had Si contents of approx. $4 \%$ at in the bulk volume.

Lu et al. [27] grew AIN crystals on $3.5^{\circ}$ off-oriented Si-polar (0001) $6 \mathrm{H}-\mathrm{SiC}$ seeds in a container of hotpressed boron nitride (HPBN) with graphite heaters and insulation at source temperatures $1830^{\circ} \mathrm{C}$. Two samples fabricated had different colorations (bluish and amber), corresponding to different silicon ( 3 and $6 \%$ at.) and carbon (5.9 and $8.1 \%$ at.) contents.

Schulz et al. [28] added SiC pieces to the source material in AIN bulk growth performed in a ceramic $\mathrm{TaC}$ container at temperatures of $2000-2200^{\circ} \mathrm{C}$. The amber-colored, polycrystalline, [0001]-textured AIN bulk contained approx. $4 \%$ at of silicon, $0.5 \%$ at of carbon, and $0.2 \%$ at of oxygen. Weak n-type conductivity was detected [29]. More recently, the group produced an AIN bulk single crystal grown on an off-oriented SiC seed which appeared dark opaque [30].

We can conclude from these literature reports that crystals grown at similar temperatures may exhibit very different $\mathrm{Si}$ and $\mathrm{C}$ contents and content ratios. Furthermore, the crystal coloration seems not to correlate with the $\mathrm{Si}$ or $\mathrm{C}$ content. However, the results are difficult to compare directly as different crucible materials, seeds, seed orientations, and growth durations have been used.

Recently, we reported on growth of bulk AIN-SiC mixed crystals on Si-face (0001) 6H-SiC seeds [31]. Growth was performed in a TaC-based setup at different growth temperatures and seed orientations in order to vary the silicon and/or carbon content in these crystals. The influence of growth conditions on optical absorption, cathodoluminescence [32], and thermally stimulated luminescence [33] was investigated. But chemical analysis was not performed and the band-gap could not be determined.

In this study, we will present additional growth experiments, including growth on AIN and SiC seeds with additional $\mathrm{SiC}$ sources. Implications of the basic growth set-up on the growth results are carefully considered. We then present chemical analysis of all samples to discuss possible correlations between impurity content and growth parameters, and to evaluate to which extent the incorporation of $\mathrm{Si}$ and/or C can be controlled during PVT growth. Finally, we investigate the influence of chemical composition on structural and optical properties, including dislocation density, phonon spectra, optical absorption, below band-gap cathodoluminescence, and near band-gap photoluminescence. With phonon and band-gap energies very similar to 'nominally pure' AIN, we will show that the grown crystals have to be considered as highly compensated, Si/C co-doped AIN.

\section{Crystal growth}

Bulk crystals are prepared by the PVT technique. The furnace is operated in high purity $\mathrm{N}_{2}$ gas at a pressure of about 500 mbar during $24 \mathrm{~h}$ of growth time. The species from the source located at the crucible bottom sublimate and re-condensate on the seed mounted on an AIN ceramic plate attached to the upper lid. A vertical thermal gradient is established by a cooling channel above the lid. Growth temperature is measured on the upper lid by a pyrometer. The growth vapor is contained in a crucible made of sintered $\mathrm{TaC}$, embedded in a graphite susceptor which is heated inductively. Thermal insulation is provided by graphite felt. Fig. 1 shows a schematic of the growth cell.

$\mathrm{TaC}$ crucibles are fabricated by pressing $\mathrm{TaC}$ powder without sintering aids. The green body is annealed in vacuum and then sintered at about $2600^{\circ} \mathrm{C}$ in a graphite susceptor in $\mathrm{N}_{2}$ atmosphere for several days. Due to the temperature field during sintering, the resulting density is slightly higher in the hotter crucible parts. In subsequent growth experiments, additional sintering leads to a slight bow and shrinkage (about $3 \%$ during 10 experiments) of the crucible. The formation of cracks leads to irreproducible results due to excessive loss of gaseous species, cf. [34]. After optimization of the sintering 
process, the occurrence of cracks in the crucible was significantly mitigated, and a single TaC crucible could be used for about 10 growth experiments. However, the crucible density did not exceed $88 \%$ of a TaC dense body even after long operation. The crucible can thus be considered as semi-open in regard to diffusion of gaseous species and equilibration of pressure e.g. during temperature ramps.

A first set of experiments is performed on Si-polar $6 \mathrm{H}-\mathrm{SiC}$ seeds of $25 \mathrm{~mm}$ diameter with only purified AIN ceramics as source material. In such case, the $\mathrm{SiC}$ seed also acts as source of silicon and carbon during growth. Growth experiments are performed at temperatures of $\mathrm{T}=1900^{\circ} \mathrm{C}, 1950^{\circ} \mathrm{C}, 2000^{\circ} \mathrm{C}$, and $2050^{\circ} \mathrm{C}$ in order to change partial pressures of the gaseous species involved in the growth process. Furthermore, impurity incorporation and intrinsic defect formation are known to depend on the facet on which growth proceeds [35]. Thus, seeds of different crystallographic orientation are employed, namely with $\varphi=0^{\circ}, 23^{\circ}, 32^{\circ}$, and $42^{\circ}$ off-orientation angle in respect to the c-axis towards the $\mathrm{m}$-plane normal, so that their surfaces approximately correspond to Al-polar (0001), (10-14), (10-13), and (10-12) AIN planes. In the second set of experiments, small pieces of single-crystalline SiC or carbon are placed on top of the AIN source material, intended to provide an additional and constant supply of silicon and carbon species during growth. As preliminary experiments indicated that placing the SiC pieces in the center of the sublimation source may deteriorate the structural quality of the growing crystal, the pieces are placed in outer areas of the source as sketched in Fig. 1 and cover about $20 \%$ of the total evaporation surface. Finally, a third set of growth experiments is performed on AIN seeds of $1.0-1.5 \mathrm{~cm}^{2}$ surface area, again with silicon carbide pieces placed on top of the source. Growth rate was in the range of $100-200 \mu \mathrm{m} / \mathrm{h}$ for crystals grown on SiC seeds and $40-60 \mu \mathrm{m} / \mathrm{h}$ for crystals grown on AIN seeds, virtually independent on growth temperature. Note that most growth experiments were repeated to check reproducibility; in case of successful growth, the crystals always yield similar properties.

If a $\mathrm{SiC}$ seed is employed, the $\mathrm{SiC}$ seed is etched on all surfaces by gaseous $\mathrm{Al}$ species which evaporate from the source at initial stages of growth $[4,36]$. As a consequence, the growth chamber is contaminated and acts itself as source for $\mathrm{Si}$ and $\mathrm{C}$ in subsequent stages of growth. While the front and side faces of the seed are soon covered by the growing crystal, Si and C supply from the backside continues steadily. However, not all of this supply will eventually reach the crystal, especially in semiopen crucibles. The amount of species that are released by etching during main stages of growth depends on density and size of 'transport channels' at the interface to the seed holder and may thus vary in time. Moreover, the formation of 'transport channels' changes slightly with every growth experiment, as it depends on seed fixation and surface roughness of the AIN ceramic plate. In extreme cases, the $\mathrm{SiC}$ crystal is consumed from the backside to such an extent that the seed is detached completely and falls down together with the crystal. The seed holder (AIN ceramic plate) itself is also roughened but not significantly contaminated by silicon or carbon.

If $\mathrm{SiC}$ pieces are used as additional source, they are uniformly etched during growth. After growth, their surfaces show macro-steps; no carbon layer or contamination with Al or $\mathrm{N}$ is observed. The backside of the SiC pieces reacts with the surrounding AIN material; after growth, the pieces are partially attached and immersed into the AIN source. This shows again that the release of $\mathrm{Si}$ and $\mathrm{C}$ is strongly enhanced due to etching by gaseous Al species from the adjacent AIN source material. However, all pieces are still existent after growth even at elevated temperatures. In one experiment, hotpressed graphite pieces are used instead of SiC pieces. The observations are similar: the pieces appear matted and etched, but they are not completely consumed during growth.

Fig. 2 shows representative crystals. The growth surface naturally depends on its crystallographic orientation. Strong faceting is observed which leads to formation of macroscopic patterns on the surface, especially on crystals grown with an off-orientation angle in respect to the c-axis. Typically, macro-terraces are formed by alternating $\{10-1 \mathrm{n}\}$ rhombohedral facets; kinks are composed of neighboring $\{01-1 \mathrm{n}\}$ and $\{1-10 \mathrm{n}\}$ rhombohedral facets. The surface of crystals grown nominally on-axis $\left(\varphi=0^{\circ}\right)$ is partly covered with hexagonal pyramids having $\{10-12\}$ rhombohedral sidewalls, cf. [37], and only small volume parts can be considered as having been grown on (0001) facets. Utmost care was taken 
to probe only crystal parts which were grown on the respective rhombohedral or basal plane facet perpendicular to the nominal growth direction. In order to evaluate the bulk content, data from the first $1 \mathrm{~mm}(0.5 \mathrm{~mm}$ for crystals grown on AIN seeds to take the low growth rate into account) above the crystal-seed interface are excluded.

Crystals grown using $\mathrm{SiC}$ seeds are always cracked. In longitudinal cuts, they are mostly aligned parallel to the growth direction [31]. Interestingly, the $\mathrm{SiC}$ seed itself is never cracked. From the cracking pattern we conclude that the cracks form after growth, most probably during cooling, due to the mismatch in thermal expansion between the $\mathrm{SiC}$ seed and the grown crystal. As expected, the crystals grown on AIN seeds are crack-free. The grown crystals are cut into wafers (i.e., cuts parallel to the seed surface), longitudinal cuts, and oblique cuts with (0001) surface. The samples are then polished on both sides to optical quality; see Ref. [31] for sample images.

\section{Chemical analysis}

Different positions on the samples are probed using an energy-dispersive X-ray (EDX) set-up attached to a scanning electron microscope (SEM). The surfaces of the samples get charged in the SEM due to their low electrical conductivity. The intensity of charging varies by sample, but the observed conditions proved to be always sufficient for reasonable X-ray analysis of the silicon content, measured as ratio $[\mathrm{Si}] /([\mathrm{Si}]+[\mathrm{Al}])$. Results are shown in Tab. 1. Unfortunately, due to their low X-ray yield and $\mathrm{K} \alpha$ radiation energy, carbon and nitrogen cannot be evaluated quantitatively using our set-up. Note that Tab. 1 additionally contains data from two experiments where the crucible exhibited cracks after the experiment while no change in growth parameters was observed during growth. In both samples 10 and 11 , grown at $\mathrm{T}=1950^{\circ} \mathrm{C} / 2000^{\circ} \mathrm{C}$ and $\varphi=42^{\circ}$, an abrupt change in coloration from yellowish to greenish occurred, which is accompanied by a sharp increase in $\mathrm{Si}$ content.

Additionally, secondary ion mass spectrometry (SIMS) is used to probe silicon, carbon, and oxygen concentrations locally on selected samples. Measurements are conducted by RTG, Berlin, Germany. Prior to measurements, the samples are coated with a $30 \mathrm{~nm}$ thick sputtered Au layer to provide for electrical conductivity. Implanted samples of epitaxial AIN layers are used to calibrate the respective concentrations. The SIMS data reach virtually constant levels after sputtering about $100 \mathrm{~nm}$ off the surface. Averaged concentrations representing the bulk properties, taken at sputtering depths between $500 \mathrm{~nm}$ and $1000 \mathrm{~nm}$, are included in Table 1. Clearly, the calibration yields excessive values for silicon in samples 1 and 5 . It is well known that assuming a linear dependence of concentration vs. count rate fails for very high impurity contents. On the other hand, the data for silicon in samples 8 and 9 grown at $\mathrm{T}=2000^{\circ} \mathrm{C}$ and $2050^{\circ} \mathrm{C}$ roughly coincide with EDX results.

Finally, two samples are investigated by Rutherford backscattering spectroscopy (RBS) using ${ }^{4} \mathrm{He}$ atoms with energies of $4.318 \mathrm{MeV}$. Measurement and analysis are performed at the Institute of Solid State Physics, University of Jena, Germany. The spectra were fitted using Ref. [38]. Sample 2 (grown on an AIN seed at $\mathrm{T}=1900^{\circ} \mathrm{C}, \varphi=23^{\circ}$, and addition of $\mathrm{SiC}$ pieces on the source top) yielded $4.0 \%$ at of silicon and $5.4 \%$ at of carbon; sample 5 (grown on a $6 \mathrm{H}-\mathrm{SiC}$ seed at $\mathrm{T}=1900^{\circ} \mathrm{C}$ and $\varphi=42^{\circ}$ ) yielded $2.0 \%$ at of silicon and $11.5 \%$ at of carbon. The Si values are significantly lower than the ones measured by EDX or SIMS, but the trend is preserved. The values for carbon are debatable as the carbon resonance peak couldn't be fitted well; the values might also be distorted in case of a surface accumulation layer of carbon on the samples.

The reason for the discrepancy of data obtained by the different methods for chemical analysis used in this study remains unclear. The probed volumes are significantly different for EDX, SIMS, and RBS measurements. On the other hand, the measurements are performed at adjacent locations on the samples, and the optical properties of the samples are virtually constant in the respective probing areas. Thus, we tentatively attribute the obtained differences to shortcomings in data acquisition and 
evaluation related to the respective method. Additionally, surface preparation might have influenced the results in different ways depending on the method.

The silicon content decreases with increasing off-orientation angle $\varphi$, being strongest on (0001) facets and decreasing on rhombohedral $\{10-1 \mathrm{n}\}$ facets with decreasing $\mathrm{n}$. Assuming that the Si supply is similar at a given growth temperature, this corresponds to differences in silicon incorporation on different facets, caused e.g. by different surface ad-atom kinetics and/or surface/step energies. Such behavior is well known from nominally undoped AIN, where crystals show a clear zonar structure [35]. Comparing samples grown at $\varphi=42^{\circ}$, the silicon content tends to decrease further with increasing growth temperature, although the $\mathrm{SiC}$ seed backside generally appears more etched at higher temperatures. As the $\mathrm{TaC}$ crucible and also the carbon susceptor appear more attacked at elevated temperatures, we conclude that more silicon evaporated and evaded through the sintered TaC crucible, effectively leading to a lower silicon supply with increasing temperature. Note that this might not be the case for growth in more dense crucibles, e.g. carbonized tantalum crucibles [24,26,34], but corresponding data are lacking.

In most crystals from the first set of experiments (i.e., grown on SiC seeds with pure AIN source), the $\mathrm{Si}$ content monotonically decreases from near the crystal-seed interface to the crystal surface. As stated before, the SiC seed surface is etched at initial stages of growth, and the corresponding species contaminate the growth cell. After the crystal has overgrown the seed, further silicon supply is limited to this contamination plus the continuing seed backside evaporation. In this sense, the monotonic decrease is attributed to the depleting growth cell contamination, while variations in silicon content from sample to sample are probably caused by differences in silicon supply from the seed backside and silicon losses through the $\mathrm{TaC}$ crucible.

In crystals grown at $\mathrm{T}=1900^{\circ} \mathrm{C}$ and $\varphi=42^{\circ}$, the silicon content is enhanced as SiC pieces are placed on top of the AIN source. On the other hand, still a decrease of Si content during growth is observed. This means that the presumably constant $\mathrm{Si}$ supply from the pieces adds up to the depleting Si supply from the growth cell contamination caused by the SiC seed as discussed above. One might wonder why a similar range of $\mathrm{Si}$ content is measured if carbon pieces are placed on top of the AIN source. As the crystal shows a very rough surface and distinct zonar structure, with areas of different Si content and coloration appearing in all stages of growth, silicon is repelled from some areas and instead incorporated on facet surfaces which can uptake a higher amount of $\mathrm{Si}$. The highest $\mathrm{Si}$ values are found in areas of black-green coloration.

For crystals grown on AIN seeds, the crystal grown at $\mathrm{T}=1900^{\circ} \mathrm{C}$ and $\varphi=42^{\circ}$ has a very similar content to its counterpart grown on a $6 \mathrm{H}-\mathrm{SiC}$ seed without $\mathrm{SiC}$ addition, but the decrease of $\mathrm{Si}$ content during growth is mitigated. In crystals grown at lower off-orientation angles, e.g. $\varphi=23^{\circ}$, we were able to incorporate as much as $18 \%$ at of silicon in the bulk volume. The even higher Si content in samples of Gu et al. [13,18] and Shi et al. [17] makes clear, however, that the silicon content in our samples does not reach the 'kinetic limit' of Si incorporation, above which the Si content does not depend on supply anymore.

The role of carbon remains more unclear, as our chemical analysis remained incomplete and partially ambiguous. The carbon content as measured by SIMS correlates to the Si content, but is always considerably lower. A systematic error in the SIMS calibration due to the high carbon and silicon content cannot be excluded. But most probably, silicon and carbon are not incorporated stoichiometrically, i.e., the crystals do not represent pseudo-binary AIN-SiC solid solutions. Note that $\mathrm{Si} C \mathrm{C}$ ratios of roughly $1: 10$ were reported also by Schulz et al. $[28,29]$ and other groups growing in tantalum based crucibles, cf. section 1. Lu et al. [27] evidenced 'stoichiometric' SiC incorporation in AIN crystals grown on SiC seeds. But in their study, growth was performed in HPBN crucibles, where a considerable amount of boron is additionally incorporated, cf. $[39,40]$. Finally, the oxygen content measured in our samples is comparable to the one found in nominally pure AIN crystals [33]. The anti-correlation between oxygen 
and silicon/carbon content is attributed to formation of volatile $\mathrm{Si}_{2} \mathrm{O}$ and $\mathrm{CO}$ species that evade from the crucible during growth.

\section{Structural properties and Raman spectra}

Regardless of growth conditions, the grown boules are all single-crystalline as evidenced by X-ray Laue and X-ray diffraction (XRD) measurements. Double-axis X-ray rocking curves (DCRC) full width at half maximum (FWHM) values of $0.07^{\circ}$ (250 arcsec) on both symmetric (0004) and asymmetric (1013) reflections as measured on sample 3 indicate the presence of slightly tilted domains, most probably originating from the $\mathrm{SiC}$ crystal used as a seed [41].

Polished cuts with Al-polar (0001) surfaces from several crystals grown on $\mathrm{SiC}$ seeds are subjected to wet chemical etching in molten $\mathrm{KOH}-\mathrm{NaOH}$ eutectic. Dislocations penetrating this surface form hexagonal pits after $120 \mathrm{~s}$ of etching at $350^{\circ} \mathrm{C}$, i.e., parameters also used for nominally pure AIN $[42,43]$. Etch pit densities in the range of $10^{5}-10^{6} \mathrm{~cm}^{-2}$ are measured independent of the growth off-orientation angle $\varphi$. Most etch pits are symmetric, indicating that the threading dislocations penetrate roughly along c-direction. A slight decrease from $4.5 \times 10^{5} \mathrm{~cm}^{-2}$ to $2.2 \times 10^{5} \mathrm{~cm}^{-2}$ is observed in crystals with $\varphi=$ $42^{\circ}$ as the growth temperature $\mathrm{T}$ changed from $1900^{\circ} \mathrm{C}$ to $2000^{\circ} \mathrm{C}$ (at similar growth rate/crystal thickness). Dislocation densities in the same range have been reported by other groups $[12,18,27,30]$. Etching at higher temperatures such as $450^{\circ} \mathrm{C}$ leads to deterioration of the etch pit rhombohedral sidewalls, whereas the etch pit density remains virtually unchanged.

Micro-Raman spectra on as-grown surfaces and polished longitudinal cuts of different crystals are recorded at room temperature under HeNe laser excitation at $632.8 \mathrm{~nm}$ focused on a $2 \mu \mathrm{m}$ diameter spot on the surface. Measurements are performed in the $150-3500 \mathrm{~cm}^{-1}$ wavenumber range; however, no Raman features are detected above $970 \mathrm{~cm}^{-1}$. Results are shown in Fig. 3. The spectra of most crystals are similar to the ones reported in literature for AIN grown on SiC seeds [3,15,24], while the spectra of samples 2, 4, and 6 roughly resemble those reported for AIN-SiC solid solutions $[8,19]$.

The spectra show Raman peaks at the position of AIN phonon energies [44]; shifts in the position of the TO phonon (610-650 $\mathrm{cm}^{-1}$ range) and the LO phonon (890-915 $\mathrm{cm}^{-1}$ range) are due to quasiphonon formation and clearly correlate to the crystallographic orientation of the probed surface [45]. The FWHM of the $\mathrm{E}_{2}^{\text {low }}$ band at $247 \mathrm{~cm}^{-1}$ lies between $1.5 \mathrm{~cm}^{-1}$ and $3.7 \mathrm{~cm}^{-1}$, the $E_{2}^{\text {high }}$ band at 656 $\mathrm{cm}^{-1}$ and the $E_{1}(\mathrm{TO})$ band at $669 \mathrm{~cm}^{-1}$ show FWHM values in the range of 4-7 $\mathrm{cm}^{-1}$ (except for samples 2,4 , and 6 , see below). The broadening as compared to nominally pure AIN is attributed to alloy scattering which leads to a significant decrease of phonon lifetimes. The lowest FWHM values are recorded for the samples 8 and 9 grown at elevated temperatures and exhibiting the lowest silicon content.

In contrast, samples 2, 4, and 6 feature a broad band peaking at $653 \mathrm{~cm}^{-1}$ with FWHM values of 54 $\mathrm{cm}^{-1}, 36 \mathrm{~cm}^{-1}$, and $57 \mathrm{~cm}^{-1}$, respectively. It correlates with an increase in Raman intensity between $500 \mathrm{~cm}^{-1}$ and $550 \mathrm{~cm}^{-1}$, attributed to disorder-induced Raman scattering in which the constraint $\mathrm{k} \approx 0$ is lifted and the Raman spectrum reflects the entire phonon density of states [19,44], and an increase in Raman intensity around $950 \mathrm{~cm}^{-1}$, which has been attributed to a SiC-like mode with $\mathrm{A}_{1}$ symmetry by Gu et al. [19]. Samples 2, 4, and 6 have been grown with the addition of SiC pieces on top of the AIN source. We suspect that the additional SiC sublimation from the source (i.e., along the axial gradient) may deteriorate the crystal's structural quality (cf. chapter 2). It can not be excluded, though, that their Raman features are a result of increased alloy scattering: The impurity content of the samples is relatively high, even though the absolute values differ as shown in Tab. 1.

Only in the spectra of samples $1,2,3,8$, and 9, as well as in the greenish areas of samples 10 and 11 (not shown here), another broad band at $240 \mathrm{~cm}^{-1}$ as well as small peaks at $602 \mathrm{~cm}^{-1}, 695 \mathrm{~cm}^{-1}$, and $723 \mathrm{~cm}^{-1}$ are detected. These crystals contain very different amounts of silicon (and presumably also carbon), but all exhibit greenish or bluish coloration caused by an optical absorption band at around 
$1.85 \mathrm{eV}$ as shown later. Tolle et al. [46] attributed bands observed in AIN-SiC solid solutions at around $600 \mathrm{~cm}^{-1}$ and $690 \mathrm{~cm}^{-1}$ to Al-C and Al-N lattice vibrations, respectively. The small peak at $723 \mathrm{~cm}^{-1}$ can be attributed to the 'silent' $\mathrm{B}_{1}$ phonon mode after Sarua et al. [47]. The nature of the broad band at $240 \mathrm{~cm}^{-1}$ remains unclear.

\section{Optical properties}

\subsection{Optical absorption}

AIN bulk crystals grown on SiC seeds exhibit different colorations depending on growth parameters and presumably on the amount of contamination [15,16,27,31]. Colorless, yellowish/amber, greenish, bluish, or black-opaque samples are reported in literature, and those colorations are also observed in our crystals as shown in Table 1.

Optical transmission spectra in the ultraviolet (UV) and visible (VIS) wavelength range are recorded at room temperature on a Perkin Elmer Lambda 950 UV/VIS Spectrometer. Appropriate apertures are used to probe only areas of interest. The transmission through the dark-green opaque samples 1 and 9 proved to be insufficient for a reliable measurement. For all other samples, the wavelengthdependent absorption coefficient $\alpha$ is calculated using the plain Beer-Lambert law, i.e. reflection is not taken into account. Results are shown in Fig. 4. The spectra show a monotonic increase with increasing photon energy, on some samples superimposed by absorption bands located around $1.85 \mathrm{eV}$ or $2.8 \mathrm{eV}$. These bands cause the samples to appear greenish/bluish or yellowish/amber, respectively, to the eye. In the UV region, all investigated samples feature a steep increase of optical absorption with the onset ranging between $3.5 \mathrm{eV}$ and $4.2 \mathrm{eV}$. The onset appears to be shifted to lower values in samples 2, 3, and 8, as well as in the greenish areas of samples 10 and 11 (not shown here). All samples are virtually opaque $\left(\alpha>100 \mathrm{~cm}^{-1}\right)$ at energies exceeding $4.45 \mathrm{eV}$ (i.e., wavelengths shorter than $275 \mathrm{~nm}$ ). In the following, we will refer to this phenomenon as 'deep-UV opacity'.

The absorption band at around $1.85 \mathrm{eV}$ is present in samples 2, 3, 7, and 8, as well as in the greenish areas of samples 10 and 11 (not shown here); note that sample 2 (grown on an AIN seed) has a rather bluish appearance and the absorption band is shifted to $1.75 \mathrm{eV}$. These samples are grown either at high temperatures (e.g. $\mathrm{T} \geq 1950^{\circ} \mathrm{C}$ and $\varphi=42^{\circ}$ ), at off-orientation angles $\varphi$ below $42^{\circ}$, or in experiments in which the $\mathrm{TaC}$ crucible exhibited cracks after growth. The first two types of crystals represent both lowest and highest detected silicon content, so this band does not correlate to silicon contamination. Optical absorption at $1.8 \mathrm{eV}$ has been attributed to carbon by Slack et al. [48]. Balkas et al. [15] and Wang et al. [16] received bluish crystals growing AIN on SiC seeds in graphite crucibles at T > $2000^{\circ} \mathrm{C}$, where the growing crystals might well get contaminated with carbon [36]. Finally, a thermal activation energy of the temperature-dependent resistivity of $1.85 \mathrm{eV}$ was found in carbon-containing AlN ceramic samples [49].

A hump in optical absorption for photon energies around $2.8 \mathrm{eV}$ is clearly seen only in sample 5 . An absorption band at $2.8 \mathrm{eV}$ is regularly observed in nominally pure AIN crystals [50,51]. There it has been attributed to nitrogen vacancies $V_{N}$ [48,52], to a transition from the valence band to negatively changed aluminum vacancies $\mathrm{V}_{\mathrm{Al}}{ }^{3-}$ [53], or to a transition from the $\mathrm{V}_{\mathrm{Al}}{ }^{3-/ 2-}$ level to a donor level in the upper half of the band-gap [51].

Deep-UV opacity is observed by all research groups growing bulk AIN in the presence of SiC that have published absorption spectra [22,54]. For example, Schlesser et al. [40] observed a 'transmission cutoff' at around $4.8 \mathrm{eV}$ for crystals grown in HPBN crucibles and attributed this to the high carbon and oxygen content in these samples. Lu et al. [55] saw the 'transmission cut-off' changing from $4.8 \mathrm{eV}$ to $4.3 \mathrm{eV}$ in crystals containing the double amount of carbon $\left(2 \cdot 10^{19} \mathrm{~cm}^{-3}\right)$, but an order of magnitude less oxygen $\left(10^{18} \mathrm{~cm}^{-3}\right.$ range) than the reference crystal. 
Disordered semiconductors may have extended absorption tails below the band-gap (Urbach tails). In the case of amorphous AIN, such Urbach tails may lead to absorption coefficients exceeding $100 \mathrm{~cm}^{-1}$ for energies above $4 \mathrm{eV}$ [56]. Urbach tails also exist in single crystals with high structural or vibrational disorder, e.g. caused by alloying or heavy doping. That said, Urbach tails may in fact contribute to deep-UV opacity in our samples depending on their impurity content. On the other hand, strong absorption bands in the energy range of $4-5 \mathrm{eV}$ are also observed in AIN samples without nominal presence of $\mathrm{SiC}$ and generally attributed to aluminum vacancies $\mathrm{V}_{\mathrm{Al}}$ [54], oxygen [48,52], or complexes involving both defects $[57,58]$. Note that the oxygen content in our samples is fairly low as shown in Tab. 1. The correlation of the absorption at $1.85 \mathrm{eV}$ to the onset of deep-UV opacity will be further discussed in the following section.

\subsection{Cathodoluminescence}

Cathodoluminescence $(\mathrm{CL})$ spectra are recorded at room temperature using a scanning electron microscope (SEM) operating at $20 \mathrm{kV}$ acceleration voltage. Spectra are recorded in the SEM fast scan mode at $100 \mathrm{nA}$ of nominal electron beam current; note that the number and kinetic energy of electrons hitting the sample - and thus the resulting $\mathrm{CL}$ intensity - depends on the magnitude of charging under electron irradiation. The scanned area is about $150 \mu \mathrm{m} \times 250 \mu \mathrm{m}$ in size. Luminescence is extracted by a parabolic Al-coated mirror, dispersed by a monochromator and recorded by a UVenhanced CCD camera. Results are shown in Fig. 5; the spectra are not corrected for sensitivity or artifacts of the set-up components. All spectra are recorded in areas near the crystal surface; an example of CL spectra evolution as a function of the distance to the seed-crystal interface is presented in Ref. [32]. Band-gap or excitonic CL is not detected in any sample, although such features are clearly visible in nominally pure AIN even at room temperature [59]: The high Si and C concentrations in the samples strongly decrease excitonic lifetime and radiative recombination.

The below band-gap CL spectra show a broad band peaking in the 3.3-3.6 eV range; additional bands or shoulders are observed at $2.8 \mathrm{eV}$ and in the range of $2.1-2.5 \mathrm{eV}$. The $\mathrm{CL}$ band in the 3.3-3.6 eV range clearly dominates the spectra in samples 3-7. Except for sample 3, they are grown at $\mathrm{T}=$ $1900^{\circ} \mathrm{C}$ and $\varphi=42^{\circ}$, have yellowish coloration or are colorless, and exhibit weak or no charging under electron irradiation. In contrast, in samples $1,2,8$, and 9, the $\mathrm{CL}$ intensity in the 2.1-2.8 eV range is in the same order of magnitude or even higher than the 3.3-3.6 eV band; the same is observed in the greenish areas of samples 10 and 11 (not shown here). These samples are grown either at higher temperature $\mathrm{T}$ or lower off-orientation angle $\varphi$, show greenish coloration (i.e., optical absorption at $1.85 \mathrm{eV})$, and exhibit strong charging.

Schulz et al. [54] have investigated below band-gap CL on 'weakly n-type' (grown with SiC addition, cf. [28]) and 'semi-insulating' (grown without nominal presence of $\mathrm{SiC}$ ) AIN crystals. Both crystals had yellowish coloration and yielded similar contents of silicon, carbon, and oxygen. The CL intensity at 3$4 \mathrm{eV}$ is observed only in the 'weakly n-type' sample, whereas the $\mathrm{CL}$ intensity in the range of 1.8-2.8 $\mathrm{eV}$ was stronger in the 'semi-insulating' sample. This coincides with our results when comparing $\mathrm{CL}$ intensity ratios with charging effects.

On the other hand, Schulz et al. [54] link the CL intensity at 3-4 eV - which they attribute to the presence of aluminum vacancies $\mathrm{V}_{\mathrm{Al}}{ }^{3-}$ in accordance to previous reports [51,53,60-62] - to a steep increase in optical absorption above $4 \mathrm{eV}$ (i.e., deep-UV opacity). Our group found a similar coincidence in 'nominally undoped' AIN, where both the $\mathrm{CL}$ bands in the 3-4 eV range and the optical absorption in the 4-5 eV range strongly decrease as a function of source purification [63]. However, all samples used in this study show deep-UV opacity regardless of the presence of the 3.3-3.6 eV CL band. This indicates that the deep-UV opacity in our samples has another (maybe additional) origin.

Summarizing absorption and $\mathrm{CL}$ results for our greenish samples, we find that optical absorption at $1.85 \mathrm{eV}$ (causing greenish/bluish coloration) is correlated to an increased deep-UV opacity (i.e., the 
onset shifts towards lower energies), but anti-correlated to the $\mathrm{CL}$ intensity in the 3.3-3.6 eV range (at least as compared to the $\mathrm{CL}$ intensity in the $2.1-2.5 \mathrm{eV}$ range). We suggest that these observations are caused by increased carbon contents in our samples with the following rationale: Refs. [40], [48], and [55] assign the absorption features to carbon. Wongchotigul et al. [64] showed that carbon-doped AIN epitaxial layers exhibit no significant luminescence in the 3-4 eV energy range. Substitutional carbon forms a DX center in AIN [65], which can absorb light with energies exceeding $4.3 \mathrm{eV}$ [66] and features a considerable stokes shift in regard to luminescence, cf. Ref. [67]. The samples exhibit weak Raman bands at $600 \mathrm{~cm}^{-1}$ attributed to Al-C lattice vibrations that are not observed in yellowish or colorless samples. Finally, the formation of cracks in the crucible during growth of samples 10 and 11 most likely opened up new sources of carbon, causing the abrupt changes in coloration from yellowish to greenish and the associated changes in Raman, optical absorption, and CL spectra.

Note that chemical analysis of our samples as presented in section 3 does not support our tentative assignment of the absorption bands to carbon. However, the compensation regime has to be considered rather than the carbon content alone in such samples with high impurity levels. Both silicon and carbon are expected to cause self-compensation and Fermi level pinning especially when present at high concentrations in AIN $[29,65,68,69]$. Vacancies and associated complexes might significantly influence compensation additionally [62], while not much is known about their formation at high impurity concentrations and under different PVT growth conditions (e.g. growth temperature). The observed high charging under electron irradiation indicates that the greenish samples are highly compensated. On the other hand, the observed variation of silicon content further emphasizes that all samples are co-doped AIN with high but independent levels of silicon and carbon incorporation: As it stands, the investigated range of PVT growth conditions and techniques of $\mathrm{SiC}$ addition does not provide for growing pseudo-binary AIN-SiC solid solutions.

\subsection{Band-gap evaluation}

The band-gap of the samples presented in this study cannot be evaluated by optical absorption due to deep-UV opacity. Thus, photoluminescence (PL) at low temperatures is used to determine near bandgap features. Fig. 6a shows a PL spectrum of the yellowish sample 5 containing approx. $4 \%$ at of $\mathrm{Si}$ (EDX) and $1 \%$ at of carbon (SIMS). Local maxima at $5.83 \mathrm{eV}, 5.65 \mathrm{eV}, 5.44 \mathrm{eV}$, and $5.26 \mathrm{eV}$ evidence that the band-gap energy in this sample is at least $5.83 \mathrm{eV}$. Similarly, sample 2 containing approx. $17 \%$ at of $\mathrm{Si}$ (EDX) and $3 \%$ at of carbon (SIMS) shows PL maxima at $5.82 \mathrm{eV}$ and $5.60 \mathrm{eV}$ (spectrum not shown here). The nature of the lower energy peaks is unclear; due to their energetic distances of approx. $200 \mathrm{meV}$ they are unlikely to originate from excitonic features or phonon replica.

Fig. 6b shows a photoluminescence excitation (PL-E) spectrum of sample 2. In this measurement, the incident wavelength (i.e., excitation energy) is changed while the luminescence intensity at a fixed wavelength $\lambda$ is monitored. At $\lambda=394 \mathrm{~nm}(3.14 \mathrm{eV})$ we expect contributions from both the $2.8 \mathrm{eV}$ and 3.3-3.6 eV luminescence bands as discussed above. A direct band-gap will manifest itself as a steep increase in PL-E intensity, as the generation of electrons and holes (which may take part in subsequent radiative recombination processes) will be strongly enhanced at this energy. It can be deduced from Fig. $6 \mathrm{~b}$ that the band-gap of sample 2 lies in the range of 5.5-5.8 eV. A steep rise in the imaginary part of the dielectric function for energies well above $5 \mathrm{eV}$ as measured by UV ellipsometry (not shown here) supports this conclusion. We conclude that the samples investigated show band-gap energies only slightly below the band-gap of pure AIN [59,70]. Note that the band-gap of AIN-SiC solid solutions containing approx. $10 \% \mathrm{SiC}$ has been calculated to be in the range of 5.2-5.6 eV [46,71,72], while Avramescu et al. [73] found weak near band-gap CL at $218 \mathrm{~nm}(5.68 \mathrm{eV})$ in an epilayer of such composition grown by metalorganic vapor deposition (MOVPE).

\section{Conclusions}


AIN single crystals are grown by physical vapor transport in the presence of SiC, i.e. by seeding on $6 \mathrm{H}-\mathrm{SiC}$ or by adding $\mathrm{SiC}$ to the AIN source material, using different growth conditions, i.e. growth temperatures $T=1900-2050^{\circ} \mathrm{C}$ and off-orientation angles in respect to [0001] $\varphi=0-42^{\circ}$. Silicon accumulates primarily on facets with low off-orientation angles. As a consequence, the Si content strongly decreases with increasing off-orientation in respect to the c-axis, i.e. on rhombohedral facets $\{10-1 \mathrm{n}\}$ with low index $\mathrm{n}$. The Si content further decreases with increasing growth temperature, most probably due to evasion of $\mathrm{Si}$ through the porous $\mathrm{TaC}$ crucible. Si depletion during growth can be mitigated by addition of SiC pieces to the AIN source material; cracking of the grown crystals can be avoided by seeding on AIN substrates. Bulk samples with Si content up to $18 \%$ at have been produced. Growing crystals with higher Si contents should be possible as the 'kinetic limit' for silicon incorporation was not reached. The chemical analysis in regard to carbon content remains ambiguous and incomplete. The data available, however, indicate that the crystals do not represent pseudo-binary AIN-SiC solid solutions.

All crystals show phonon bands at the positions of AIN phonon energies, and a low-temperature bandgap exceeding $5.8 \mathrm{eV}$, which is only slightly lower then the band-gap of pure AIN. On the other hand, their optical absorption spectra are dominated by a steep increase above 3.5-4.2 eV, rendering them opaque for photon energies above $4.45 \mathrm{eV}$, regardless of silicon content.

Due to significant differences in Raman, optical absorption, and below band-gap cathodoluminescence (CL) spectra, two different types of samples can be separated. In yellowish/amber and colorless samples, the steep increase in optical absorption (deep-UV opacity) starts at $4.2 \mathrm{eV}$. Their CL is dominated by a broad band in the range of 3.3-3.6 eV, and their charging under electron irradiation is low. Such samples are produced on rhombohedral $(1-102)$ facets $\left(\varphi=42^{\circ}\right)$ at $\mathrm{T}=1900-2000^{\circ} \mathrm{C}$ and show silicon contents (as measured by EDX) of up to $6 \%$ at.

In contrast, greenish/bluish samples are produced at lower off-orientation angle $\varphi$, at higher temperature $\mathrm{T}$, or in experiments during which the TaC crucible cracked. In such samples, the onset of deepUV opacity is typically shifted towards lower energies, and another absorption band at $1.75-1.85 \mathrm{eV}$ is observed. The $\mathrm{CL}$ band at 3.3-3.6 eV is of lower intensity as compared to CL bands in the 2.1-2.8 eV range. The samples show additional peaks in the Raman spectra which cannot be attributed to 'pure' AIN phonon modes. Finally, they get strongly charged under electron irradiation and are thus highly compensated. As the properties described above are virtually independent in regard to the measured silicon content, we suggest that they are caused by increased carbon content in the samples. This assignment cannot be deduced from our chemical analysis, but we assume that self-compensation of silicon and carbon, as well as formation of intrinsic defects, leads to a complex compensation scenario in the samples.

In summary, the investigated range of PVT growth conditions and techniques of SiC addition does not provide for growing pseudo-binary AIN-SiC solid solutions. Instead, we consider the grown crystals as highly compensated, Si/C co-doped AIN. The high concentrations of impurities govern their optical properties, and presumably also the electrical behavior, via complex compensation regimes.

\section{Acknowledgements}

This work was substantially supported by the Deutsche Forschungsgemeinschaft (DFG) under No. BI781/5-1. The authors greatly acknowledge additional contributions from: Pascal Schley, Fachgebiet Experimentalphysik I, Technische Universität IImenau, Germany (UV ellipsometry); Lutz Kirste, Fraunhofer-Institut für angewandte Festkörperphysik (IAF) Freiburg, Germany (X-ray diffraction measurements); Thomas Lichthorn, Tobias Geiger, and Elena Epelbaum, Department of Materials Science 6 (I-MEET), University of Erlangen, Germany (optical measurements, wet chemical etching, and sample preparation). 


\section{References:}

[1] D. Ehrentraut, Z. Sitar, MRS Bull. 34 (2009) 259

[2] S. Yamada, J.-I. Kato, S. Tanaka, I. Suemune, A. Avramescu, Y. Aoyagi, N. Teraguchi, A. Suzuki, Appl. Phys. Lett. 78 (2001) 3612

[3] Y. Shi, Z. Y. Xie, L. H. Liu, B. Liu, J. H. Edgar, M. Kuball, J. Crystal Growth 233 (2001) 177

[4] B. M. Epelbaum, M. Bickermann, A. Winnacker, Mater. Sci. Forum 433-436 (2003) 983

[5] V. Noveski, R. Schlesser, S. Mahajan, S. Beaudoin, Z. Sitar, MRS Internet J. Nitride Semicond. Res. 9 (2004) 2

[6] P. Heimann, B. M. Epelbaum, M. Bickermann, S. Nagata, A. Winnacker, Phys. Status Solidi C 3 (2006) 1575

[7] R. Yakimova, A. Kakanakova-Georgieva, G. R. Yazdi, G. K. Gueorguiev, M. Syväjärvi, J. Crystal Growth 281 (2005) 81

[8] M. Anikin, D. Chaussende, E. Pernot, O. Chaix-Pluchery, H. Roussel, M. Pons, R. Madar, Mater. Sci. Forum 527-530 (2006) 1501

[9] J. H. Edgar, Z. Gu, L. Gu, D. J. Smith, Phys. Status Solidi A 203 (2006) 3720

[10] P. Lu, J. H. Edgar, R. G. Lee, J. Chaudhuri, J. Crystal Growth 300 (2007) 336

[11] G. R. Yazdi, M. Syväjärvi, R. Yakimova, J. Crystal Growth 300 (2007) 130

[12] M. Miyanaga, N. Mizuhara, T. Kawase, S. Fujiwara, M. Shimazu, H. Nakahata, T. Kawase, J. Crystal Growth 300 (2007) 45

[13] Z. Gu, J. H. Edgar, B. Raghothamachar, M. Dudley, D. Zhuang, Z. Sitar, D. W. Coffey, J. Mater. Res. 22 (2007) 675

[14] H. Kamata, K. Naoe, K. Sanada, N. Ichinose, J. Crystal Growth 311 (2009) 1291

[15] C. M. Balkaş, Z. Sitar, T. Zheleva, L. Bergman, R. Nemanich, R. F. Davis, J. Crystal Growth 179 (1997) 363

[16] S. Wang, B. Raghothamachar, M. Dudley, A. G. Timmerman, MRS Symp. Proc. 892 (2006) FF30-06

[17] Y. Shi, B. Liu, L. Liu, J. H. Edgar, E. A. Payzant, J. M. Hayes, M. Kuball, MRS Internet J. Nitride Semicond. Res. 6 (2001) 5

[18] Z. Gu, L. Du, J. H. Edgar, E. A. Payzant, L. Walker, R. Liu, M. H. Engelhard, MRS Internet J. Nitride Semicond. Res. 10 (2005) 5

[19] Z. Gu, J. H. Edgar, E. A. Payzant, H. M. Meyer, L. R. Walker, A. Sarua, M. Kuball, MRS Symp. Proc. 831 (2005) E3.1.1

[20] R. Dalmau, R. Schlesser, B. J. Rodriguez, R. J. Nemanich, Z. Sitar, J. Crystal Growth 281 (2005) 68

[21] R. Dalmau, R. Schlesser, Z. Sitar, Phys. Status Solidi C 2 (2005) 2036

[22] Yu. N. Makarov, O. V. Avdeev, I. S. Barash, D. S. Bazarevskiy, T. Yu. Chemekova, E. N. Mokhov, S. S. Nagalyuk, A. D. Roenkov, A. S. Segal, Yu. A. Vodakov, M. G. Ramm, S. Davis, G. Huminic, H. Helava, J. Crystal Growth 310 (2008) 881

[23] E. N. Mokhov, A. D. Roenkov, Yu. A. Vodakov, S. Yu. Karpov, M. S. Ramm, A. S. Segal, Yu. A. Makarov, H. Helava, Mater. Sci. Forum 433-436 (2003) 979

[24] E. N. Mokhov, O. V. Avdeev, I. S. Barash, T. Yu. Chemekova, A. D. Roenkov, A. S. Segal, A. A. Wolfson, Y. N. Makarov, M. G. Ramm, H. Helava, J. Crystal Growth 281 (2005) 93

[25] T. Yu. Chemekova, 1, O. V. Avdeev, I. S. Barash, E. N. Mokhov, S. S. Nagalyuk, A. D. Roenkov, A. S. Segal, Yu. N. Makarov, M. G. Ramm, S. Davis, G. Huminic, H. Helava, Phys. Status Solidi C 5 (2008) 1612

[26] R. R. Sumathi, R. U. Barz, P. Gille, T. Straubinger, Phys. Status Solidi C (2011) in press / DOI 10.1002/pssc.201000941

[27] P. Lu, J. H. Edgar, C. Cao, K. Hohn, R. Dalmau, R. Schlesser, Z. Sitar, J. Crystal Growth 310 (2008) 2464

[28] T. Schulz, K. Irmscher, M. Albrecht, C. Hartmann, J. Wollweber, R. Fornari, Phys. Status Solidi RRL 1 (2007) 147

[29] K. Irmscher, T. Schulz, M. Albrecht, C. Hartmann, J. Wollweber, R. Fornari, Physica B 401-402 (2007) 323

[30] C. Hartmann, M. Albrecht, J. Wollweber, private communication.

[31] O. Filip, M. Bickermann, B. M. Epelbaum, P. Heimann, A. Winnacker, J. Crystal Growth 312 (2010) 2522

[32] M. Bickermann, B. M. Epelbaum, O. Filip, P. Heimann, A. Winnacker, Phys. Status Solidi C 7 (2010) 1746

[33] M. Bickermann, S. Schuster, B. M. Epelbaum, O. Filip, P. Heimann, S. Nagata, A. Winnacker, Phys. Status Solidi C 8 (2011) 2104

[34] C. Hartmann, J. Wollweber, M. Albrecht, I. Rasin, Phys. Status Solidi C 3 (2006) 1608 
[35] M. Bickermann, P. Heimann, B. M. Epelbaum, Phys. Status Solidi C 3 (2006) 1902

[36] B. Epelbaum, D. Hofmann, M. Bickermann, A. Winnacker, Mater. Sci. Forum 389-393 (2002) 1445

[37] O. Filip, B. M. Epelbaum, M. Bickermann, P. Heimann, S. Nagata, A. Winnacker, Mater. Sci. Forum 615-617 (2009) 983

[38] N. P. Barradas, C. Jeynes, R. P. Webb, Appl. Phys. Lett. 71 (1997) 291

[39] M. Albrecht, J. Wollweber, M. Rossberg, M. Schmidbauer, C. Hartmann, R. Fornari, Appl. Phys. Lett. 88 (2006) 211904

[40] R. Schlesser, R. Dalmau, D. Zhuang, R. Collazo, Z. Sitar, J. Crystal Growth 281 (2005) 75

[41] C. Seitz, Z. Herro, B. Epelbaum, R. Hock, A. Magerl, J. Appl. Cryst. 39 (2006) 17

[42] M. Bickermann, S. Schmidt, B. M. Epelbaum, P. Heimann, S. Nagata, A. Winnacker, J. Crystal Growth 300 (2007) 299

[43] D. Zhuang, J. H. Edgar, Mater. Sci. Eng. R 48 (2005) 1

[44] V. Yu. Davydov, Yu. E. Kitaev, I. N. Goncharuk, A. N. Smirnov, J. Graul, O. Semchinova, D. Uffmann, M. B. Smirnov, A. P. Mirgorodsky, R. A. Evarestov, Phys. Rev. B 58 (1998) 12899

[45] M. Bickermann, B. M. Epelbaum, P. Heimann, Z. G. Herro, A. Winnacker, Appl. Phys. Lett. 86 (2005) 131904

[46] J. Tolle, R. Roucka, A.V.G. Chimeshya, P. A. Crozier, D. J. Smith, I.S.T. Tsong, J. Kouvetakis, Solid State Sciences 4 (2002) 1509

[47] A. Sarua, S. Rajasingam, M. Kuball, N. Garro, O. Sancho, A. Cros, A. Cantarero, D. Olguin, B. Liu, D. Zhuang, J. H. Edgar, MRS Symp. Proc. 798 (2004) Y5.17

[48] G. A. Slack, T. F. McNelly, J. Crystal Growth 42 (1977) 560

[49] R. W. Francis, W. L. Worrell, J. Electrochem. Soc. 123 (1976) 430

[50] M. Bickermann, B. M. Epelbaum, A. Winnacker, J. Crystal Growth 269 (2004) 432

[51] M. Bickermann, B. Epelbaum, O. Filip, P. Heimann, S. Nagata, A. Winnacker, Phys. Status Solidi B 246 (2009) 1181

[52] G. A. Slack, L. J. Schowalter, D. Morelli, J. A. Freitas Jr, J. Crystal Growth 246 (2002) 287

[53] A. Sedhain, L. Du, J. H. Edgar, J. Y. Lin, H. X. Jiang, Appl. Phys. Lett. 95 (2009) 262104

[54] T. Schulz, M. Albrecht, K. Irmscher, C. Hartmann, J. Wollweber, R. Fornari, Phys. Status Solidi B 248 (2011) 1513

[55] P. Lu, R. Collazo, R. F. Dalmau, G. Durkaya, N. Dietz, Z. Sitar, Appl. Phys. Lett. 93 (2008) 131922

[56] J. A. Guerra, L. Montañez, O. Erlenbach, G. Galvez, F. De Zela, A. Winnacker, R. Weingärtner, J. Phys: Conf. Ser. 274 (2011) 012113

[57] M. Bickermann, A. Münch, B. M. Epelbaum, O. Filip, P. Heimann, S. Nagata, A. Winnacker, J. Appl. Phys. 103 (2008) 073522

[58] M. Bickermann, B. M. Epelbaum, O. Filip, P. Heimann, S. Nagata, A. Winnacker, Phys. Status Solidi C 7 (2010) 21

[59] G. M. Prinz, A. Ladenburger, M. Feneberg, M. Schirra, S. B. Thapa, M. Bickermann, B. M. Epelbaum, F. Scholz, K. Thonke, R. Sauer, Superlatt. Microstruct. 40 (2006) 513

[60] K. B. Nam, M. L. Nakarmi, J. Y. Lin, H. X. Jiang, Appl. Phys. Lett. 86 (2005) 222108

[61] T. Hoshi, T. Koyama, M. Sugawara, A. Uedono, J. F. Kaeding, R. Sharma, S. Nakamura, S. F. Chichibu, Phys. Status Solidi C 5 (2008) 2129

[62] P. N. Pantha, A. Sedhain, J. Li, J. Y. Lin, H. X. Jiang, Appl. Phys. Lett. 96 (2010) 131906

[63] M. Bickermann, B. M. Epelbaum, O. Filip, P. Heimann, M. Feneberg, S. Nagata, A. Winnacker, Phys. Status Solidi C 7 (2010) 1743

[64] K. Wongchotigul, N. Chen, D. P. Zhang, X. Tang, M. G. Spencer, Mater. Lett. 26 (1996) 223

[65] P. Bogusławski, J. Bernholc, Phys. Rev. B 56 (1997) 9496

[66] C. G. Van de Walle, "Carbon Impurities and Yellow Emission", presented at the 9th International Conference on Nitride Semiconductors (ICNS-9), Glasgow, Great Britain, 2011.

[67] J. L. Lyons, A. Janotti, C. G. Van de Walle, Appl. Phys. Lett. 97 (2010) 152108

[68] M. Hermann, F. Furtmayr, A. Bergmaier, G. Dollinger, M. Stutzmann, M. Eickhoff, Appl. Phys. Lett. 86 (2005) 192108

[69] T. Ive, O. Brandt, H. Kostial, K. J. Friedland, L. Däweritz, K. H. Ploog, Appl. Phys. Lett. 86 (2005) 024106

[70] M. Feneberg, R. A. R. Leute, B. Neuschl, K. Thonke, M. Bickermann, Phys. Rev. B 82 (2010) 075208

[71] G. K. Safaraliev, Yu. M. Tairov, V. F. Tsvetkov, Sov. Phys. Semicond. 25 (1991) 865

[72] A. P. Dmitriev, N. V. Evlakov, A. S. Furman, Semicond. 30 (1996) 60

[73] A. Avramescu, H. Hirayama, Y. Aoyagi, S. Tanaka, J. Crystal Growth 234 (2002) 435 
Figure and Table captions:

Fig. 1: Schematic of the growth cell. (a), (b), and (c) refer to the first, second, and third set of experiments. The big arrow denotes the net flow of growth species, small arrows indicate possible sources for SiC contamination.

Fig. 2: Grown crystals with longitudinal or oblique cuts for sample preparation. The crystals refer to sample 5 (left) and sample 10 (right) in Table 1. The ruler shows labels on a centimeter scale.

Fig. 3: Room temperature micro-Raman spectra (logarithmic scale), probed in areas near the crystal surface. Sample labeling follows Table 1 . The spectra are shifted vertically each by a factor of 5 for clarity.

Fig. 4: Room temperature optical absorption spectra, probed in areas near the crystal surface. Sample labeling follows Table 1.

Fig. 5: Room temperature cathodoluminescence (CL) spectra (logarithmic scale), probed in areas near the crystal surface. Sample labeling follows Table 1.The spectra are shifted vertically each by a factor of 10 for clarity, the spectra of sample 2 is shifted additionally. Note that measurement artifacts (higher order maxima produced by the monochromator grating) of the dominating band at about $3.45 \mathrm{eV}$ are visible in the spectra at $1.8 \mathrm{eV}$ and $1.2 \mathrm{eV}$; the respective energies are shown as vertical lines.

Fig. 6: (a) Near band-gap photoluminescence (PL) of sample 5 recorded at 10-12 K with $193 \mathrm{~nm}$ ArF laser excitation; (b) photoluminescence excitation (PL-E) intensity of sample 2 at $8 \mathrm{~K}$ and $394 \mathrm{~nm}$ (3.14 $\mathrm{eV}$ ) monitoring wavelength, recorded at the SUPERLUMI beamline at DESY, Hamburg, Germany.

Tab. 1: Coloration, strength of charging effect under electron irradiation $\left(60 \mathrm{nA} / \mathrm{mm}^{2}\right.$ current density at $20 \mathrm{kV}$ ), and chemical analysis by EDX and SIMS of representative crystals. All crystals are grown on $6 \mathrm{H}-\mathrm{SiC}$ seeds with pure AIN source except where noted. An arrow indicates a transient behavior in the bulk from $1 \mathrm{~mm}$ above the seed towards the crystal surface as measured in longitudinal cuts. 
Fig. 1

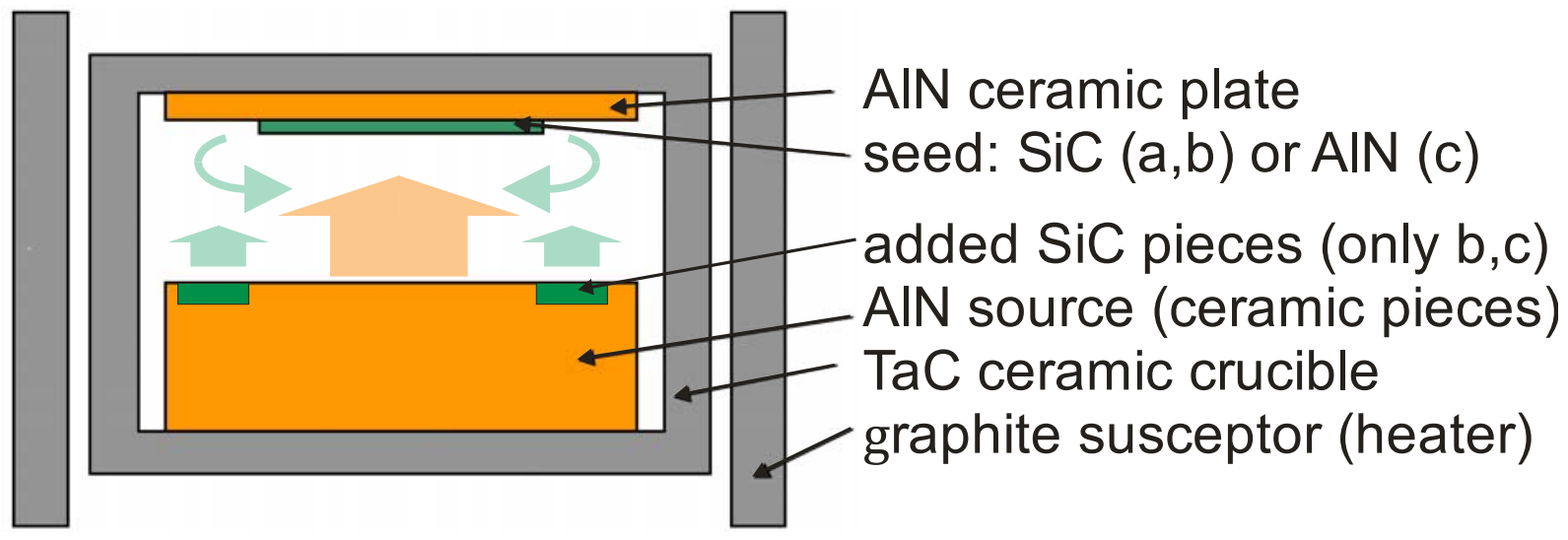


Fig. 2:
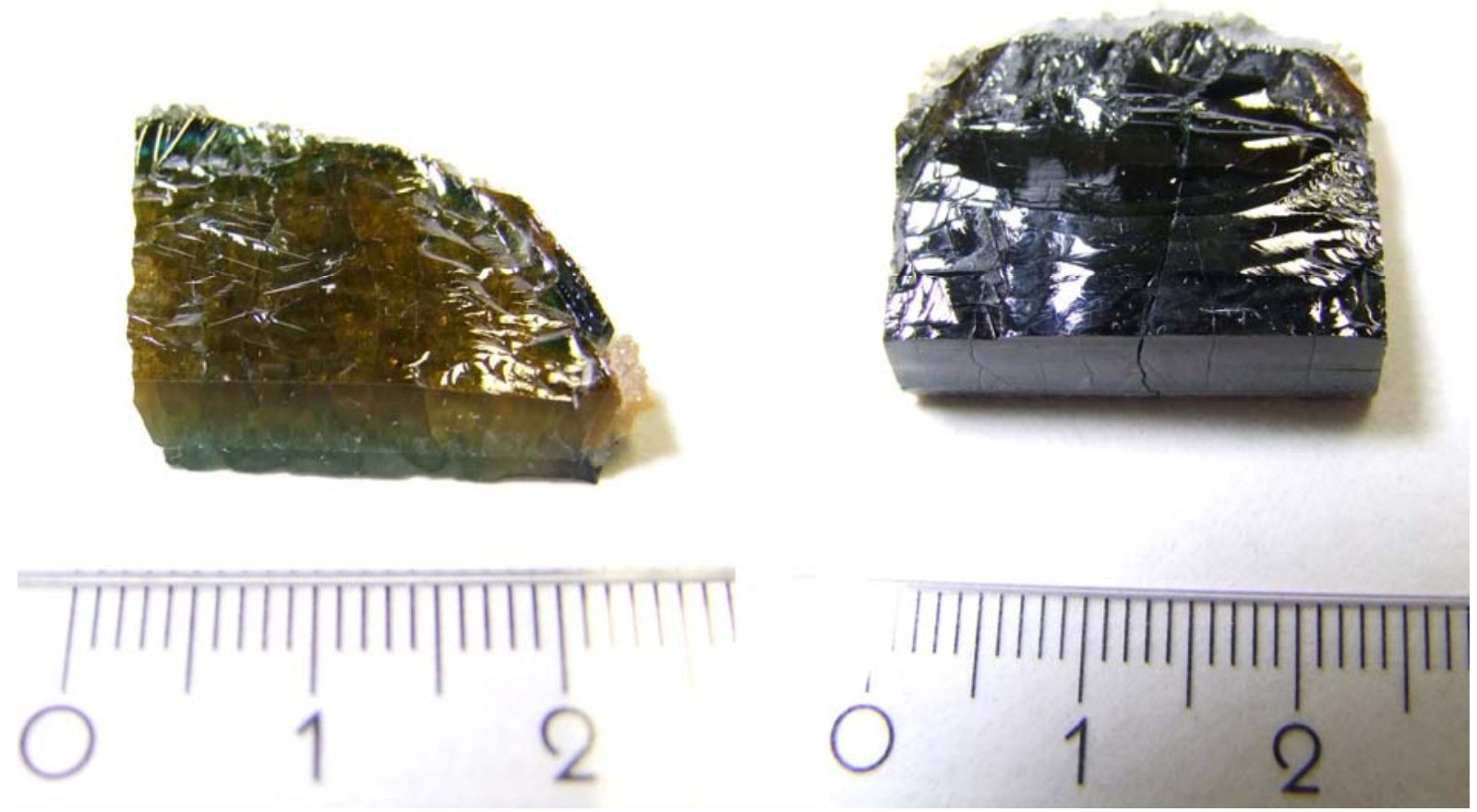
Fig. 3:

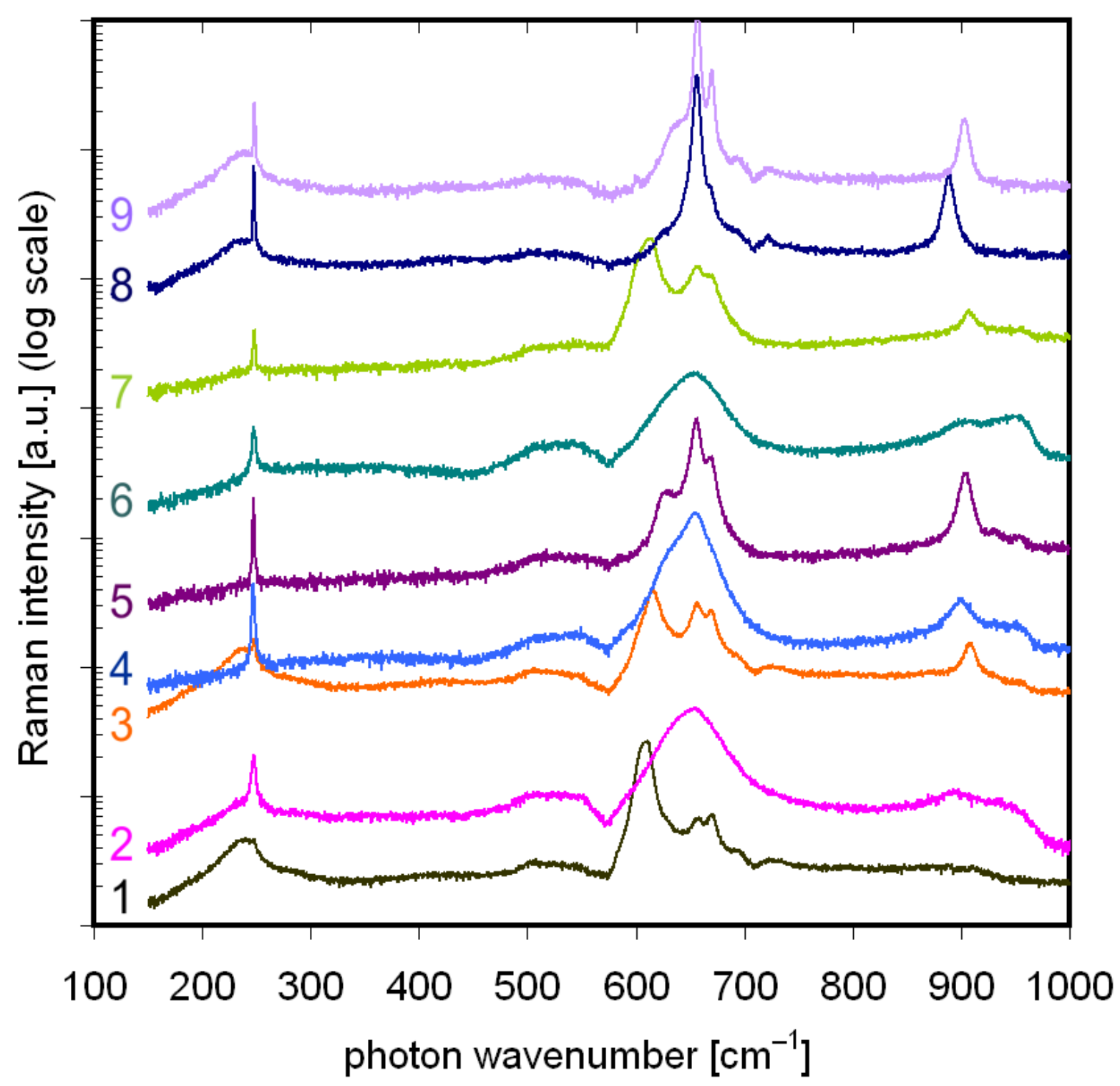


Fig. 4:

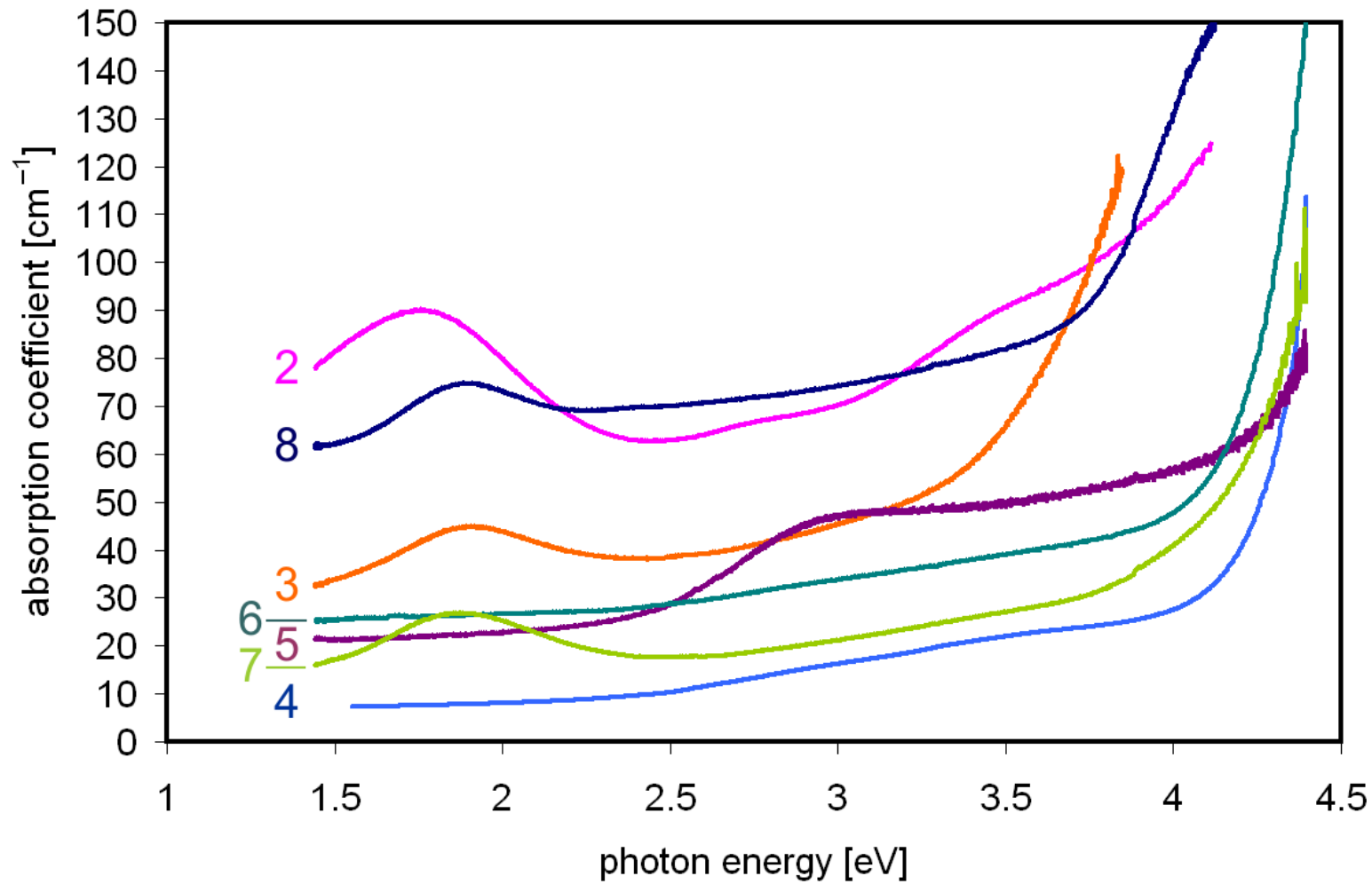


Fig. 5:

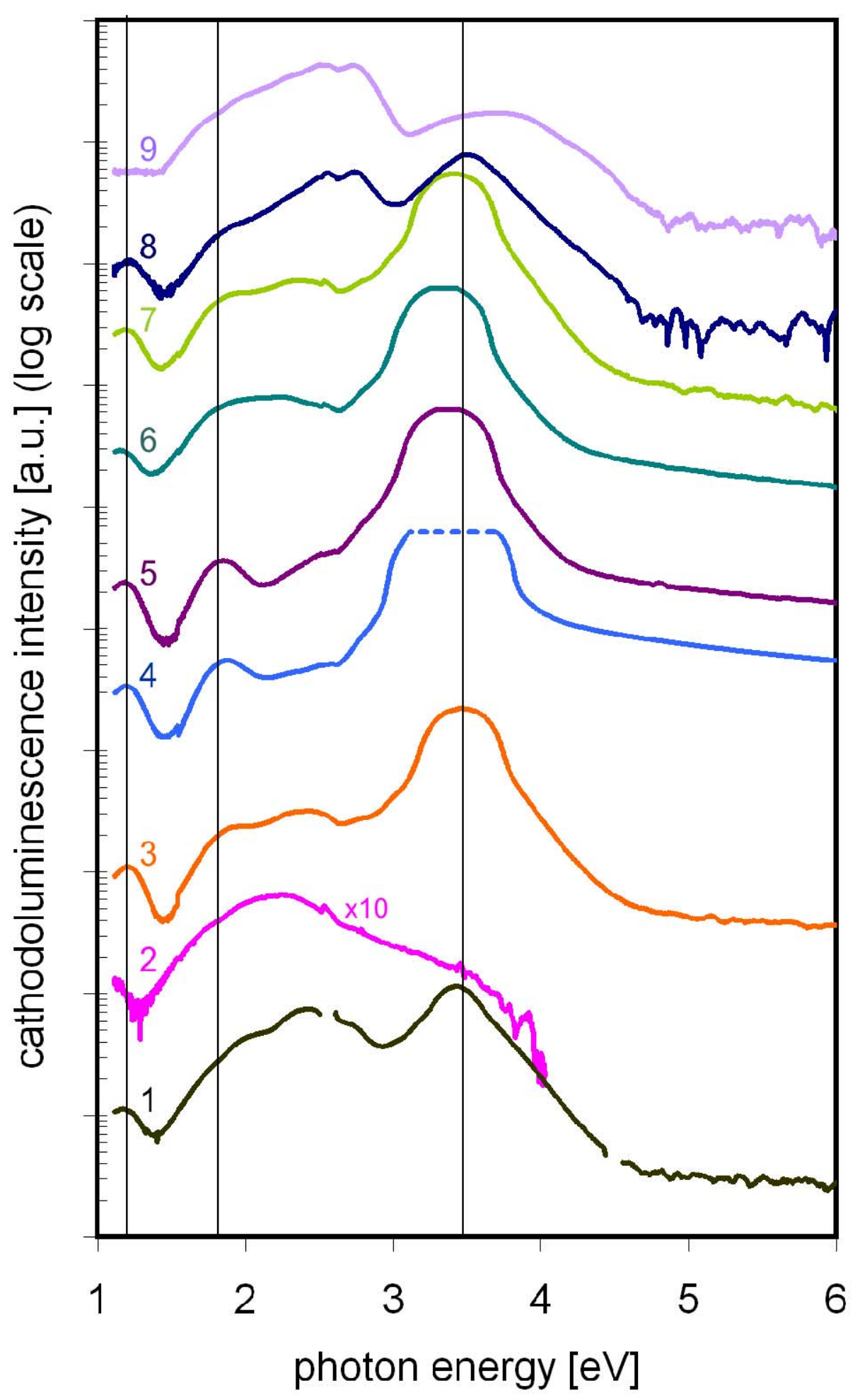


Fig. 6:
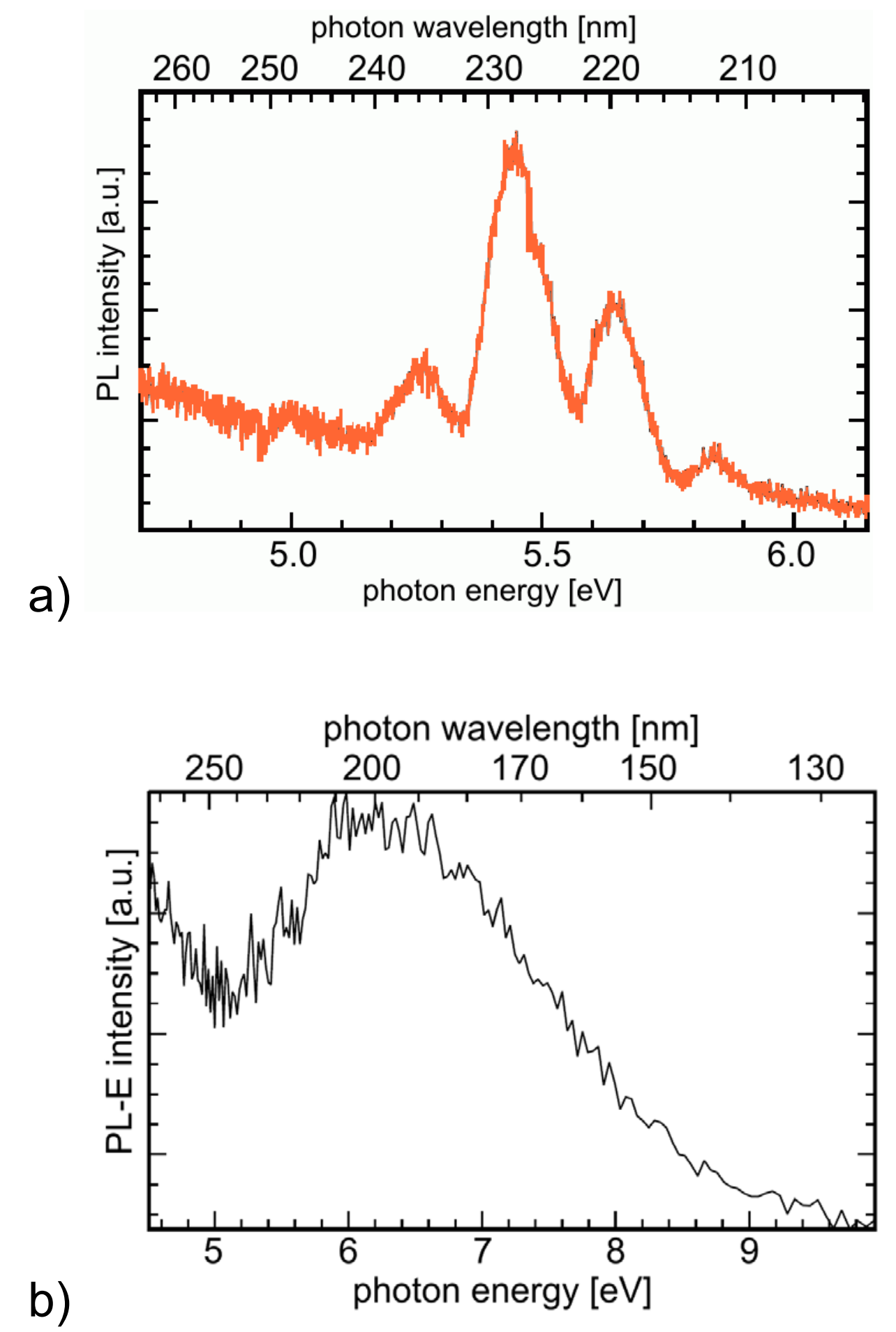
Table 1:

\begin{tabular}{|c|c|c|c|c|c|c|c|}
\hline & \multirow{2}{*}{$\begin{array}{l}\text { Crystal (temperature } \mathrm{T} \text {, } \\
\text { off-orientation angle } \varphi \text { ) }\end{array}$} & \multirow[t]{2}{*}{ coloration } & \multirow[t]{2}{*}{ charging } & \multirow{2}{*}{$\begin{array}{c}\text { EDX } \\
{[\text { Si] in \% at }}\end{array}$} & \multicolumn{2}{|c|}{- SIMS } & \multirow[b]{2}{*}[\mathrm{O}]{ in $10^{18} \mathrm{~cm}^{-3}$} \\
\hline & & & & & [Si] in \% at & {$[\mathrm{C}]$ in $\%$ at } & \\
\hline 1 & $1900^{\circ} \mathrm{C}, 0^{\circ}$ & black-green & strong & $14.5 \rightarrow 13.2$ & & & \\
\hline 2 & $1900^{\circ} \mathrm{C}, 23^{\circ}$ on AIN seed & bluish & strong & $15.8-17.9$ & 52.2 & 3.1 & 1.3 \\
\hline 3 & $1900^{\circ} \mathrm{C}, 32^{\circ}$ & black-green & strong & $13.0 \rightarrow 7.1$ & & & \\
\hline 4 & $1900^{\circ} \mathrm{C}, 42^{\circ}$ on AIN seed & yellowish & none & $6.0 \rightarrow 3.5$ & & & \\
\hline 5 & $1900^{\circ} \mathrm{C}, 42^{\circ}$ & yellowish & none & $6.0 \rightarrow 3.8$ & $20.2 \rightarrow 17.3$ & $1.2 \rightarrow 1.0$ & $1.6 \rightarrow 1.8$ \\
\hline 6 & $1900^{\circ} \mathrm{C}, 42^{\circ}$ with $\mathrm{SiC}$ addition & colorless & none & $11.7 \rightarrow 7.1$ & & & \\
\hline 7 & $1900^{\circ} \mathrm{C}, 42^{\circ}$ with $\mathrm{C}$ addition & (varying) & strong & $3.5-11.0$ & & & \\
\hline 8 & $2000^{\circ} \mathrm{C}, 42^{\circ}$ & greenish & weak & $4.1-4.5$ & 4.0 & 0.3 & 2.4 \\
\hline 9 & $2050^{\circ} \mathrm{C}, 42^{\circ}$ & black-green & strong & $0.8-4.9$ & 2.7 & 0.3 & 3.0 \\
\hline \multirow[t]{2}{*}{10} & $1950^{\circ} \mathrm{C}, 42^{\circ}$, lower part & yellowish & none & $5.0 \rightarrow 2.1$ & & & \\
\hline & upper part & greenish & strong & $5.7-6.0$ & & & \\
\hline \multirow[t]{2}{*}{11} & $2000^{\circ} \mathrm{C}, 42^{\circ}$, lower part & yellowish & none & $0.9-1.2$ & & & \\
\hline & upper part & greenish & strong & $4.2-4.8$ & & & \\
\hline
\end{tabular}

